\title{
Effect of smoking on the response to nonsurgical periodontal therapy
}

\author{
N.A. Nassrawin
}

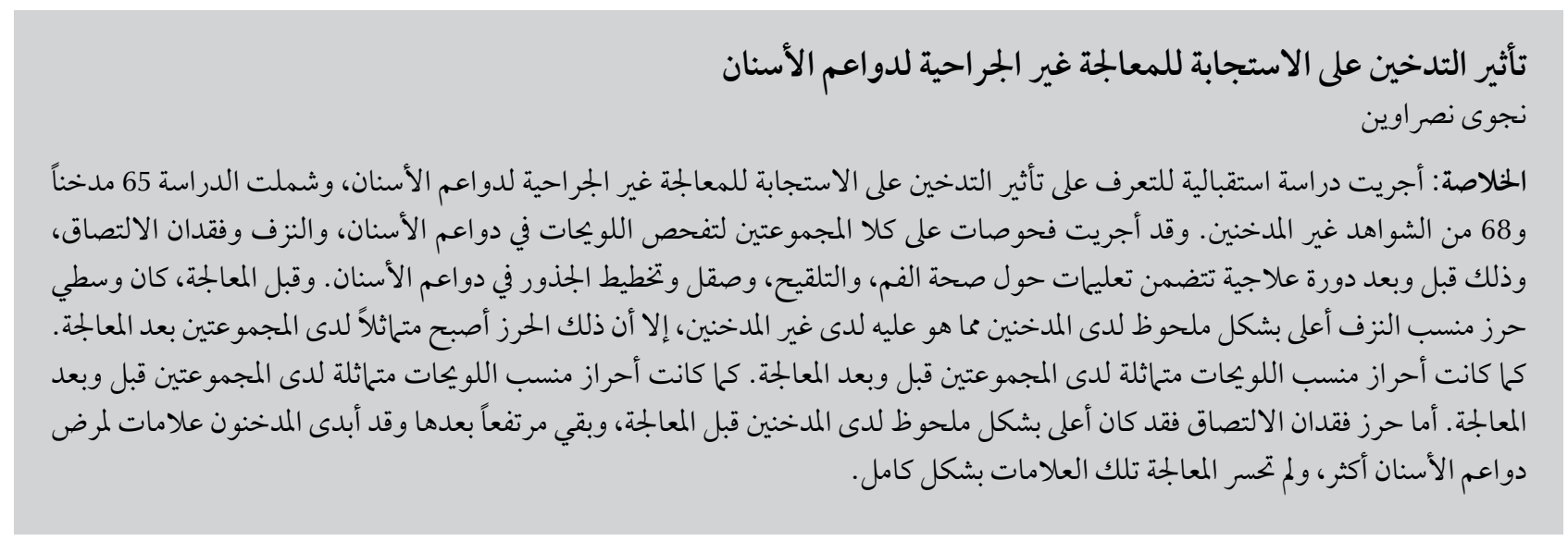

ABSTRACT To investigate the influence of smoking on the response of nonsurgical periodontal treatment, a prospective study was carried out on 65 smokers and 68 nonsmoker controls. Both groups were examined periodontally for plaque, bleeding and loss of attachment, before and after a course of treatment with oral hygiene instructions, scaling, root planning periodontal and polishing. Before treatment, mean bleeding index score was significantly higher in smokers than nonsmokers but scores were similar after treatment. Plaque index scores were similar in both groups before and after treatment. Loss of attachment score was significantly higher in smokers before treatment and remained higher after treatment. Smokers showed more signs of periodontal disease, and treatment did not reverse this fully.

\section{Effets du tabagisme sur la réponse au traitement parodontal non chirurgical}

RÉSUMÉ Afin d'étudier l'influence du tabagisme sur la réponse au traitement parodontal non chirurgical, une étude prospective a été menée sur 65 fumeurs et un groupe de contrôle de 68 non-fumeurs. Les deux groupes ont fait l'objet d'examens parodontaux, à la recherche de plaque dentaire, de saignements et de déchaussements, avant et après un traitement comprenant des conseils en matière d'hygiène bucco-dentaire, un détartrage, un surfaçage radiculaire et un polissage. Avant le traitement, l'indice moyen de saignements était nettement plus élevé chez les fumeurs que chez les non-fumeurs, mais les résultats après le traitement étaient proches. Les indices de plaque dentaire étaient similaires dans les deux groupes, avant et après le traitement, alors que les indices de déchaussements étaient nettement plus élevés chez les fumeurs avant le traitement et le sont restés après le traitement. Les fumeurs présentaient plus de signes de maladie parodontale ; le traitement n'a pas complètement inversé cette tendance. 


\section{Introduction}

Tobacco smoking has been identified as a risk factor for poor periodontal health in several studies over the years, and it has been reported that smokers have more severe periodontal diseases than former smokers or nonsmokers [1-7]. However, the exact mechanism behind the negative effect of smoking on the oral disease process is not fully understood. Conflicting results have been found in studies of the effect of smoking on gingival crevicular fluid flow [2-5], subgingival microflora [6-10], plaque index, $[1,2]$, gingival capillary density and bleeding sites [11-13], bone loss and periodontal attachment [14], and gingival recession $[15,16]$. RiveraHidalgo summarized many previous studies about the effect of smoking on periodontal health [14].

Any of these factors could alter the response of smokers to periodontal therapy if there are effects on periodontal wound healing after surgical or nonsurgical therapy. There are many reports that wound healing is poorer among smokers compared to nonsmokers $[10,17-21]$. In a systematic review of the effect of smoking on nonsurgical periodontal therapy Labriola et al. concluded that there was no evidence of a difference in gain in clinical attachment between smokers and nonsmokers or a reduction of bleeding on probing [20].

The aim of the present study was to investigate the influence of smoking on the response to nonsurgical periodontal treatment.

\section{Methods}

This prospective study was carried out during 2006 at Queen Alia Military Hospital in Amman, Jordan.

\section{Sample}

Participants wererecruited from patients presenting for periodontal treatment to the periodontal clinic of the dental department. All patients meeting the study criteria over the study period and willing to follow the study protocol were included in the sample. The study group was 65 male patients who had smoked a minimum of 10 cigarettes/day for more than 2 years. Their age range was $32-51$ years (mean 43.1 years). The control group was 68 male nonsmokers who had not smoked before. Their age range was 35-50 years (mean 41.2 years). Ex-smokers were excluded. Both groups were medically fit. None of the participants were undergoing antibiotic or anti-inflammatory therapy or had undergone such therapy in the previous 6 months. Patients with gross oral pathology were excluded, and only those with chronic adult periodontitis and who reported that they brushed their teeth at least once/day were included in the study. Females were excluded to avoid confounding effects due to hormoneinduced microcirculatory changes.

\section{Data collection}

\section{Assessment}

Both study groups were examined periodontally for plaque accumulation, gingival bleeding and loss of attachment for all teeth except the third molar or any tooth that had caries or restoration at the cervical area. Presence of supragingival plaque was recorded according to the Löe and Silness plaque index [22]. The bleeding index was examined in response to probing according to Ainamo and Bay [23], using a calibrated Williams periodontal probe. Loss of attachment was read to the nearest millimetre at 6 areas (mesiobuccal, midbuccal, distobuccal, mesiolingual, midlingual and distolingual). The probe was positioned parallel to the long axis of the tooth and interproximally as close as possible to the contact point.

\section{Intervention}

Both control and study groups were subjected to nonsurgical treatment by one periodontist. Patients were treated and data collected by the same periodontist throughout the treatment period.

Periodontal parameters were recorded for each patient before the start of treatment. At the first session all patients were given oral hygiene instructions about methods of toothbrushing and using interdental cleaning aids for 2 weeks. Treatment sessions consisted of debridment of supra- and subgingival oral deposits through scaling and root planing using Gracey curettes. At each visit for scaling and root planing, the oral cavity was divided into 2 halves (upper and lower left side and upper and lower right side). Polishing was carried out after that. The treatment sessions lasted for 30-40 minutes and the course of treatment was between 2 and 5 months.

An appointment was scheduled for all patients 6-8 weeks after the last session of treatment. Compliance with the instructions that had been given to them was recorded, then patients were re-examined and all periodontal parameters were recorded again.

\section{Statistical analysis}

Statistical analysis was performed using SPSS, version 9. Unpaired Student $t$-test was used, with the level of significance at $P<0.05$

\section{Results}

All selected patients continued to the end of the study; no participants were excluded for any reason. Before therapy the mean values of all 3 periodontal parameters were higher in smokers than nonsmokers (Table 1). Mean scores for bleeding index and loss of attachment were significantly higher $(P=0.02$ and $P<0.001$ respectively), whereas the difference in plaque index was not significant.

Table 1 shows the mean scores for both groups after nonsurgical periodontal treatment. There was a reduction in 


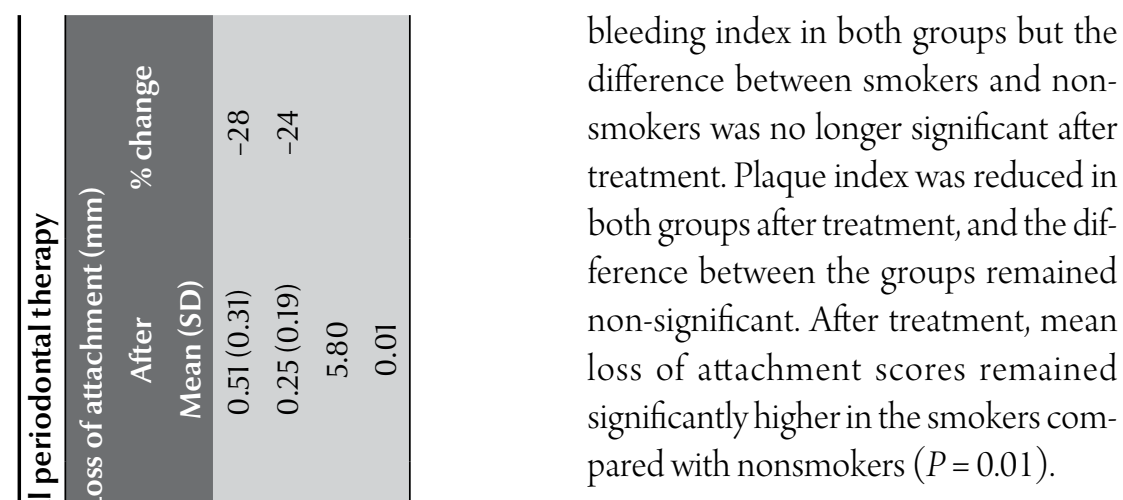

\section{Discussion}

The present study assessed the periodontal status of smokers and nonsmokers in response to nonsurgical treatment in both groups. Smokers showed more signs of periodontal disease at the start of the study, and treatment did not reverse this fully.

Preber and Bergström reported that nonsurgical periodontal treatment was an efficient means of reducing the probing depth of pathological pockets [2]. The magnitude of probing depth reduction was smaller in smokers than in nonsmokers. In another study, Ah et al. found that smokers did not respond as well as nonsmokers to non-surgical periodontal therapy, and smokers had less reduction in pocket depth [19]. Machtei et al. reported that after mechanical periodontal therapy nonsmokers showed much greater attachment gain $(13.9 \%)$ compared with smokers $(9.0 \%)$, and that the reduction in probing depth was $50 \%$ greater among nonsmokers than smokers [24]. Previous studies $[17,19,21,24]$ agree with our results, where loss of attachment was significantly higher in smokers before treatment and remained higher after treatment.

In a study conducted by Calsina et al. no difference was found between smokers and nonsmokers in plaque index [25], which is in agreement with this study, where no difference between smokers and nonsmokers was recorded either before or after the treatment. The result may be explained by the aggravated effect of nicotine on the periodontal tissues, especially if accompanied by plaque.

Another study by Ah et al. reported that nonsmokers had more bleeding on probing than smokers at the initial examination but less bleeding than smokers after phase 1 therapy, which was explained by a decrease in the wound healing process in smokers [19]. In another study, Calsina et al. found that the difference in bleeding on probing was statistically significant between smokers, former smokers and nonsmokers and smokers showed less bleeding [25]. The authors explained the results as due to reduced vascular inflammatory reaction in response to the vasoconstriction induced by tobacco at the gingival level. The results of our study are consistent with the results of both earlier studies $[19,25]$, where the difference between smokers and nonsmokers was significant before but not after treatment. Smokers exhibited a greater reduction in bleeding on probing after nonsurgical periodontal treatment.

The results of this and previous $[2,19,24,25]$ studies are consistent with the impression of many practitioners that smoking has a negative effect on the periodontium, both before and after periodontal treatment. Smokers are affected more than nonsmokers and respond less favourably to therapy.

In conclusion, this short-term study has shown that smokers had more signs of periodontal disease than nonsmokers and treatment did not reverse this fully, which may imply a negative influence of smoking on the periodontal healing response. This study has some limitations, such as the small sample size and the short period of the study. To overcome these limitations, further studies are needed over longer periods of time with a larger number of participant to study the effect of smoking on the periodontium as a whole. 


\section{References}

1. Bergström J, Preber $\mathrm{H}$. The influence of cigarette smoking on the development of experimental gingivitis. Journal of periodontal research, 1986, 21:663-76.

2. Preber H, Bergström J. The effect of non-surgical treatment on periodontal pockets in smokers and non-smokers. Journal of clinical periodontology, 1985, 13:319-23.

3. Holmes LG. Effects of smoking and/or vitamin C on crevicular fluid flow in clinically healthy gingiva. Quintessence international, 1990, 21:191-5.

4. Pangborn RM, Sharon IM. Visual deprivation and parotid response to cigarette smoking. Physiology and behavior, 1971, 6(5):559-61.

5. McLaughlin WS et al. The immediate effects of smoking on gingival fluid flow. Journal of clinical periodontology, 1993, 20:448-51.

6. Preber $\mathrm{H}$, Bergström J, Linder LE Occurrence of periopathogens in smoker and non-smoker patients. Journal of clinical periodontology, 1990, 19:667-71.

7. Stoltenberg JL et al. Association between cigarette smoking, bacterial pathogens, and periodontal status. Journal of periodontology, 1993, 64:1225-30.

8. Van der Velden $U$ et al. Effect of smoking and periodonta treatment on the subgingival microflora: a retrospective study. Journal of clinical periodontology, 2003, 30(7):603-10.

9. Zambon JJ et al. Cigarette smoking increases the risk for subgingival infection with periodontal pathogens. Journal of periodontology, 1996, 67(10 Suppl.):1050-4.

10. Grossi SG et al. Response to periodontal therapy in diabetics and smokers. Journal of periodontology, 1996, 67(10 Suppl.):1094-102.

11. Palmer RM. Should quit smoking interventions be the first part of initial periodontal therapy? Journal of clinical periodontology, 2005, 32:867-8.

12. Mirbod SM, Ahing SI, Pruthi VK. Immuno-histochemical study of vestibular gingival blood vessels density and internal circumference in smokers and nonsmokers. Journal of periodontology, 2001, 72:1318-23.
13. Lindeboom JA et al. Effect of smoking on the gingival capillary density, assessment of gingival capillary density with orthogonal polarization spectral imaging. Journal of clinical periodontology, 2005, 32:1208-12.

14. Rivera-Hidalgo F. Smoking and periodontal diseases. Periodontology 2000, 2003, 32:50-8.

15. Gunsolley JC et al. The effect of smoking on individuals with minimal periodontal destruction. Journal of periodontology, 1998, 69:165-70.

16. Múller HP, Stadermann S, Heinecke A. Gingival recession in smokers and non-smokers with minimal periodontal disease. Journal of clinical periodontology, 2002, 29:129-36.

17. Preber $\mathrm{H}$, Bergström J. Cigarette smoking in patients referred for periodontal treatment. Scandinavian dental research, 1986, 94:102-8.

18. Preber H, Bergström J. Effect of cigarette smoking on periodontal healing following surgical therapy. Journal of clinical periodontology, 1990, 17:324-8.

19. Ah MKB et al. The effect of smoking on the response to periodontal therapy. Journal of clinical periodontology, 1994, 21:91-9

20. Labriola A, Needleman I, Moles DR. Systematic review of the effect of smoking on nonsurgical periodontal therapy. Periodontology, 2000, 37:124-137.

21. Preber $\mathrm{H}$, Linder L, Bergström J. Periodontal healing and periopathogenic microflora in smokers and nonsmokers. Journal of clinical periodontology, 1995, 22:946-52.

22. Löe H, Silness J. Periodontal disease in pregnancy. I. Prevalence and severity. Acta odontologica scandinavica, 1963, 21:533-51.

23. Ainamo J, Bay l. Problems and proposals for recording gingivitis and plaque. International dental journal, 1975, 25:229-35.

24. Machtei EE et al. Radiographic and clinical responses to periodontal therapy. Journal of periodontology, 1998, 69:590-5.

25. Calsina G, Ramón JM, Echeverría JJ. Effect of smoking on periodontal tissues. Journal of clinical periodontology, 2002, 29(8):771-6. 